\title{
CURRÍCULOS OFICIAIS E PRATICADOS NA FORMAÇÃO DOCENTE EM HISTÓRIA NA FACULDADE DE FILOSOFIA SANTA DOROTÉIA
}

\author{
PRATICED AN OFICIAL CURRICULAONTEACHERS' EDUCATION IN HISTORY IN THE FACULTY OF \\ PHILOSOPHY SANTA DOROTEIA
}

Aline Nunes Ferreirinha de Souza' Inês Barbosa de Oliveira²

\begin{abstract}
Resumo: Este artigo apresenta algumas das alterações curriculares efetuadas no curso de licenciatura em História da Faculdade de Filosofia Santa Dorotéia (FFSD), entre os anos de 2001-2009, relacionando estas modificações com as políticas educacionais do período e os principais documentos legais referentes à área do currículo e da formação docente, vigentes em nosso país, no período temporal em análise. Com foco teórico-epistemológico-metodológico nas pesquisas nos/dos/com os cotidianos, podemos dizer que desafia as regras acadêmicas hegemônicas em relação às pesquisas em Educação, do currículo e da formação de professores, importando-se não só com documentos e normas, mas também com os acontecimentos cotidianos. O texto dialoga com as ações efetivamente desenvolvidas pelos praticantes de currículos que atuavam na instituição, professores e estudantes. Usando a noção de Currículo como Criação Cotidiana, a pesquisa de doutorado na origem deste texto se consubstancia como uma pesquisa qualitativa. A instituição educacional foco deste estudo dedicou-se durante anos à formação docente, através da oferta de variados cursos de licenciatura, dentre eles a licenciatura em História. Além disso, ao longo do texto tecemos relações entre a estrutura curricular da licenciatura em História da FFSD e a formação docente na área, em geral, e os currículos praticados pelos seus docentes em particular. Para dar conta destes objetivos, é necessário dialogar com diversificadas fontes, com destaque para as documentais e as bibliográficas, abordando questões que envolvem os currículos da licenciatura em História, seus praticantes e sua relação com a formação dos professores e professoras desta disciplina na Santa Dorotéia.
\end{abstract}

Palavras-chave: Currículo. Licenciatura em História. FFSD.

Abstract: This article presents some of de curricular changes made in the History course at the Faculty of Philosophy Santa Dorotéia (FFSD), between 2001-2009, relating these changes to the educational policies of to the area of curriculum and teacher training, in force in our country, in the time period under analysis. With a theoreticalepistemological-methodological focus on research in/of/with everyday life, we can say that it challenges the hegemonic academic rules in relation to research in Education, curriculum and teacher training, caring not only for documents and standards, but also with everyday events. The text dialogues with the actions affectively developed by curriculum practitioners who worked at the institution, teachers and students. Using the notion of Curriculum as Everyday Creation, the doctoral research at the origin of this is embodied as a qualitative research. The education institution has dedicated itself for years to teacher, through the offering of various undergraduate courses, including a degree in History. In addition, throughout the text we weave relationships between the curriculum structure of the degree in History of FFSD and teacher training in the area, in general, and the curricula practiced by its teachers in particular. In order to achieve these objectives, it is necessary to dialogue with diverse sources, with emphasis on documentary and bibliographic ones, addressing issues involving the curriculum of the degree in History, its practitioners and its relationship with the formation of teachers of this discipline in Santa Dorotéia.

Keywords: Curriculum. Degree in History. FFSD.

\footnotetext{
${ }^{1}$ Doutoranda em educação na Universidade Estácio de Sá, professora do CEJA Pedro Américo e Técnica em Assuntos Educacionais na Universidade Federal Fluminense. E-mail: nineferreirinha@bol.com.br. Orcid: https://orcid.org/0000-0001-6296-3265.

${ }^{2}$ Doutora em Sciences Et Théories de L'éducation - Université de Sciences Humaines de Strasbourg. Professora titular da Universidade do Estado do Rio de Janeiro (UERJ) e professora adjunta do Programa de pós-graduação em Educação da Universidade Estácio de Sá. E-mail: inesbo2018@gmail.com. Orcid: https://orcid.org/0000-0003-41013919.
} 
Resumen: Este artículo presenta algunos de los cambios curriculares realizados en la carrera de Historia de la Facultad de Filosofía Santa Dorotéia (FFSD), entre 2001-2009, relacionando estos cambios con las políticas educativas de la época y los principales documentos legales referentes a la área de currículo y formación docente, vigente en nuestro país, en el período analizado. Con un enfoque teórico-epistemológico-metodológico de la investigación en / de / con la vida cotidiana, podemos decir que desafía las reglas académicas hegemónicas en relación a la investigación en Educación, currículo y formación docente, atendiendo no solo a los documentos y estándares, pero también con los acontecimientos cotidianos. El texto dialoga con las acciones efectivamente desarrolladas por los practicantes del currículo que trabajaron en la institución, docentes y estudiantes. Usando la noción de Currículum como creación cotidiana, la investigación doctoral en el origen de este texto se materializa como una investigación cualitativa. La institución educativa que es el foco de este estudio se ha dedicado durante años a la formación del profesorado, a través de la oferta de diversas carreras de grado, entre ellas la licenciatura en Historia. Además, a lo largo del texto se tejen relaciones entre la estructura curricular de la licenciatura en Historia de las FFSD y la formación docente del área, en general, y los currículos practicados por sus docentes en particular. Para lograr estos objetivos es necesario dialogar con diversas fuentes, con énfasis en las documentales y bibliográficas, abordando temas que involucran los planes de estudio de la licenciatura en Historia, sus practicantes y su relación con la formación de profesores de esta disciplina en Santa Dorotéia.

Palabras clave: Currículum. Licenciada en Historia. FFSD.

\section{INTRODUÇÃO}

Este artigo pretende apresentar algumas das alterações curriculares efetuadas no curso de licenciatura em História da Faculdade de Filosofia Santa Dorotéia (FFSD), entre os anos de 2001-2009, relacionando estas modificações com as políticas educacionais do período e os principais documentos legais referentes à área do currículo e da formação docente, vigentes em nosso país, no período temporal em análise.

Para dar conta dos objetivos deste texto, o iniciamos contextualizando brevemente a história da Faculdade de Filosofia Santa Dorotéia, estabelecendo paralelos entre sua trajetória e a da cidade de Nova Friburgo-RJ. Ademais, apresentamos aspectos que demonstrem a relevante contribuição da FFSD à formação docente em nível de licenciatura para a cidade de Nova Friburgo e municípios em seu entorno, dando foco neste artigo para o curso de licenciatura em História.

Somando-se ao que já foi exposto, pretendemos ainda demonstrar quais motivos/fatores conduziram a Santa Dorotéia a fazer duas (2001 e 2006) das três alterações curriculares efetuadas pela Instituição ao longo do século XXI, relacionando estas alterações ao contexto histórico-educacional brasileiro e à legislação norteadora dos campos do currículo e da formação docente, no país.

Com o intuito de dar conta dos objetivos já citados mostrou-se necessário o uso de diversificadas fontes, contribuindo para o enriquecimento do trabalho de pesquisa que tem como destaque as fontes documentais e bibliográficas. É importante frisar que a diversidade de fontes de pesquisa é uma das principais características dos estudos nos/dos/com os cotidianos, norteador da pesquisa e apresentados neste artigo.

Um artigo com foco teórico-epistemológico-metodológico nas pesquisas nos/dos/com os cotidianos desafia as regras acadêmicas hegemônicas em relação às pesquisas desenvolvidas no campo da Educação, do currículo e da formação de professores, pois considera como importante fonte de pesquisa as narrativas dos sujeitos e os acontecimentos cotidianos, para além das referências teóricas e documentais. Nesse sentido, neste método de pesquisa todas essas fontes são consideradas (ALVES, 2008), tendo em vista o objetivo de tecer conhecimentos que considerem os "praticantes da vida cotidiana" (CERTEAU, 1994) na compreensão da realidade estudada.

Outra característica marcante dos estudos nos/dos/com os cotidianos é o reconhecimento da parcialidade de todo pesquisador e de todo conhecimento, dispensando e mesmo rejeitando a busca pela tão propalada imparcialidade do sujeito cognoscível frente ao seu objeto de pesquisa imposta pelas metodologias de pesquisa hegemônicas na modernidade.

Esta característica dos estudos nos/dos/com os cotidianos proporcionaram-nos a possibilidade de mergulhar numa pesquisa sobre a Faculdade de Filosofia Santa Dorotéia. Sendo a pesquisadora uma egressa da licenciatura em pauta e desta instituição educacional, não podemos deixar de mencionar a 
ISSN 1983-1579

Doi: $10.22478 /$ ufpb.1983-1579.2020v13n3.54568

http://periodicos.ufpb.br/ojs2/index.php

enorme satisfação que é poder desenvolver este trabalho de pesquisa.

Em conformidade com o que foi dito anteriormente, fica evidente que este artigo envolve os campos da Educação e da História, dando ênfase aos estudos de currículo e sua relação com a formação de professores e professoras na licenciatura em História, entre os anos de 2001-2009, perpassando parte da história e trajetória da Faculdade de Filosofia Santa Dorotéia, uma instituição educacional privada de nível superior.

Conforme nossos objetivos, trazemos nas considerações finais o modo como as mudanças/alterações promovidas na organização curricular do curso de licenciatura em História da FFSD adequaram-se às regras estabelecidas pelos documentos legais brasileiros referentes à área do currículo em História e das exigências em relação à formação docente para a disciplina, na licenciatura.

\section{FACULDADE DE FILOSOFIA SANTA DOROTÉIA E A CIDADE DE NOVA FRIBURGO: breve histórico}

Começamos, assim, esta primeira parte de nosso artigo com um breve histórico da cidade de Nova Friburgo e da Faculdade de Filosofia Santa Dorotéia (FFSD) com o intuito de situar o leitor em relação a estes relevantes atores que compõem o trabalho de pesquisa na origem deste texto. Iniciamos com a cidade de Nova Friburgo-RJ e posteriormente, a partir da década de 1950, demonstramos como a FFSD passou a compor o cotidiano de Nova Friburgo num entrecruzamento de trajetórias da cidade e da instituição educacional.

A cidade de Nova Friburgo está localizada na região serrana do estado do Rio de Janeiro. Pode ser considerada uma cidade de médio porte e conta atualmente com uma população em torno de 190.000 habitantes. É considerada um polo regional de grande relevância para os municípios ao seu entorno.

Vários municípios circunvizinhos de Nova Friburgo, como: Bom Jardim, Cordeiro, Cantagalo, Macuco, Duas Barras, Sumidouro, dentre outros buscam na cidade atendimento médico de maior complexidade, capacitação e qualificação profissional de variados níveis, vagas de emprego, comércio mais variado, dentre outras atividades que esses municípios não apresentam, não têm de forma suficiente ou com a mesma qualidade/quantidade.

Outra característica que atrai pessoas de todas as regiões do estado do Rio de Janeiro e até do país para Nova Friburgo é o clima ameno e agradável que durante muitos anos foi inclusive considerado salubre. A condição climática da cidade acabou fomentando o turismo no município e a instalação de diversas instituições educacionais de formação secundarista, algumas em regime de externato e outras em regime de internato, desde os anos finais do século XIX.

Atualmente, Nova Friburgo destaca-se no estado do Rio de Janeiro por ser um polo produtor de moda íntima, flores e hortaliças. Outras importantes atividades econômicas do município são as indústrias metal-mecânica de variado porte, o comércio e o turismo. Para entendermos a trajetória da cidade, considero necessário contextualizar historicamente o município.

Nova Friburgo surgiu como vila no ano de 1820, período em que a Província do Rio de Janeiro já se destacava como grande produtora de café, produto este que durante muitos anos foi o principal pilar da economia brasileira.

É relevante afirmar que a vila de Nova Friburgo se localizava no meio do caminho entre a atual cidade de Cantagalo, na época grande produtora de café, e a cidade do Rio de Janeiro, naquele momento capital do país. Esta localização geográfica era privilegiada e estratégica naquele momento histórico.

Daremos um salto no tempo, mais precisamente para a primeira década de 1900 que se tornou marcante para a história da cidade em tela, pois foi nesse período que se instalaram em Friburgo três indústrias do ramo têxtil, dando então novos contornos para a sua trajetória. Daí em diante, o processo de industrialização consolidou-se, incluindo décadas mais tarde indústrias dos ramos de plástico, vestuário e metalurgia.

Já nos anos 1950, destacamos o início da trajetória da Faculdade de Filosofia Santa Dorotéia (FFSD) 
que passou a compor e a entrelaçar-se com a história e o cotidiano de Nova Friburgo.

A Faculdade de Filosofia Santa Dorotéia (FFSD), instituição educacional foco deste artigo, foi uma instituição de nível superior privada e confessional, fundada na década de 1950, na cidade de Nova Friburgo-RJ que se dedicou ao longo de toda sua trajetória à formação de professores em nível de licenciatura.

A origem da FFSD se deu a partir de um Departamento Feminino, inaugurado em 1956, vinculado à Faculdade de Filosofia Nossa Senhora Medianeira (FFNSM), instituição educacional que tinha como sede o Colégio Anchieta, na cidade de Nova Friburgo.

Desde o início de suas atividades educacionais o Departamento Feminino ofertou os cursos de Pedagogia e Letras Clássicas. E no ano de 1957 conseguiu realizar o objetivo de ter uma sede própria, inaugurada no mês de novembro. Foi este mesmo prédio que a Faculdade Santa Dorotéia utilizou até o encerramento de suas atividades em 2014.

Imagem 1 - Fachada do prédio da Faculdade de Filosofia Santa Dorotéia

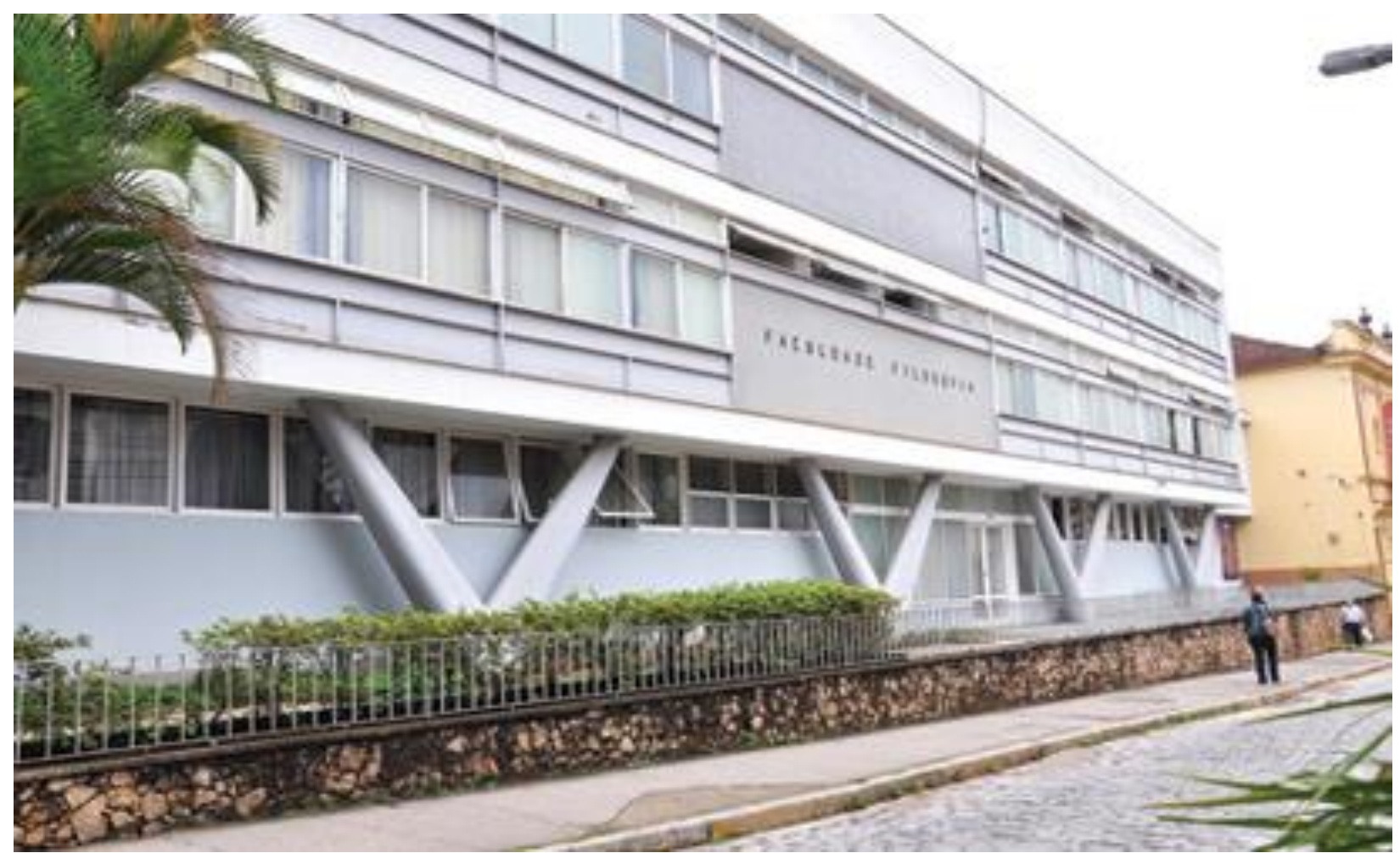

Fonte: http://acervo.avozdaserra.com.br/

No início da década de 1960, o Departamento Feminino passou a oferecer mais três cursos de licenciatura: História, Ciências Sociais e Letras Neolatinas.

O ano de 1965 foi marcante para a FFSD, pois foi nesse ano que o Departamento Feminino da Faculdade de Filosofia Nossa Senhora Medianeira solicitou ao Ministério da Educação e Cultura (MEC) sua autonomia e posterior transformação em Faculdade de Filosofia Santa Dorotéia. Isso se deu através de um acordo entre os padres jesuítas e as irmãs dorotéias, pois a Faculdade de Filosofia Nossa Senhora Medianeira transferiu-se para a cidade de São Paulo em busca da expansão de suas atividades educacionais.

O ano de 1966 foi marcado pela adaptação à nova condição de Faculdade autônoma. Um período de transição para a agora Faculdade de Filosofia Santa Dorotéia (FFSD), mantida pela Congregação de Santa Dorotéia do Brasil. A seguir apresentamos alguns dos motivos que a madre Maria Angelina de Magalhães Carvalho alegou para o MEC como favoráveis à pretensão de transformar o Departamento Feminino da FFNSM em Faculdade de Filosofia Santa Dorotéia: 
1. Em primeiro lugar, cresce vertiginosamente a população escolar de nível médio da cidade de Nova Friburgo, não havendo outra escola de nível superior.

2. Em segundo lugar, a Faculdade serve não somente a Nova Friburgo, mas também a grande faixa do Estado do Rio de Janeiro- Bom Jardim, Cordeiro, Sumidouro, Cantagalo, Carmo, Duas Barras, Cachoeiras de Macacu, Trajano de Morais- bem como à Zona da Mata de Minas Gerais. (SANTOS e CHALOUB, 2008, p. 52)

As palavras de madre Angelina deixam claro que a Faculdade de Filosofia Santa Dorotéia nasceu como uma faculdade que tinha como principal objetivo ofertar cursos de licenciatura que propiciassem formação docente de nível superior para professores de Nova Friburgo e municípios próximos, destacando-se como a única escola de nível superior existente na região nos anos 1960.

O fato de ser a única instituição educacional de nível superior na região de Nova Friburgo, na década de 1960, fez da Santa Dorotéia uma relevante opção de formação docente pós-secundária e, também, uma oportunidade de formação superior para os que não podiam continuar seus estudos na capital, por motivos diversos. Ademais, era uma das restritas opções de formação profissional para as mulheres na década de 1960, pois a profissão de professora era uma das únicas alternativas de inserção feminina no mercado de trabalho à época.

Depois de todo o processo de transformação do Departamento Feminino em uma faculdade autônoma e das adaptações necessárias da Instituição à sua autonomia, a Santa Dorotéia permaneceu trilhando seu caminho na oferta de cursos de licenciatura por mais algumas décadas.

Vale lembrar que todo este processo de implantação e autonomia da FFSD ocorreu ao longo do período inicial da ditadura civil-militar que se instalou no nosso país no ano de 1964. Este redirecionamento político nacional afetou diretamente a instituição educacional em estudo, a trajetória do município de Nova Friburgo e os caminhos do nosso país.

No ano de 1968, o governo militar estabeleceu o Ato Institucional $n^{\circ} 5$ que endureceu os ditames ditatoriais no Brasil. Outra relevante mudança estabelecida neste ano que afetou diretamente as instituições de ensino superior, dentre elas a Santa Dorotéia, foi a Lei 5.540/68, a chamada Lei da Reforma Universitária. Observe as palavras de Santos e Chaloub (2008, p. 64) acerca das mudanças promovidas pela referida lei:

A lei 5.540/68 estabeleceu o fim da cátedra e a departamentalização, instituindo os cursos "parcelados" através dos créditos, o que desfazia o corporativismo das turmas com alunos que seguiam juntos por vários anos, adotou o vestibular unificado e classificatório para abolir a figura do excedente, em vez de procurar resolver o problema da falta de vagas.

O estabelecimento da Lei de Reforma Universitária fez com que a FFSD promovesse uma série de mudanças na sua organização administrativa, pedagógica, curricular, dentre outras para poder se adaptar a ela. Como se não bastasse, no ano de 1971, o governo militar sancionou uma nova lei de âmbito educacional, a Lei 5.692/71 que alterava substantivamente a LDB anterior. O advento desta nova legislação educacional trouxe mais uma mudança para a Faculdade de Filosofia Santa Dorotéia: a oferta de uma licenciatura de curta duração para atender a necessidade de profissionalização docente rápida para atuação no ensino fundamental, organizado por áreas pela Lei 5.692/71.

Faz-se necessário destacar que ao longo do período ditatorial, de 1964 a 1985, a FFSD manteve uma postura de não enfrentamento direto em relação ao regime militar, porém, manteve seu compromisso de fomentar eventos diversificados na área da educação e da cultura que fizessem um contraponto ao momento de opressão política vivenciado neste período da nossa história. Na FFSD, em Nova Friburgo, se a conjuntura nacional de opressão política não chegava a se refletir com intensidade a ponto de intimidar totalmente professores e alunos, o clima de medo existia e obrigava que as falas fossem cuidadosamente pensadas antes de serem externadas. As "paredes tinham ouvidos" e muitas suspeitas havia sobre a presença de policiais ou militares à paisana, ou mesmo de algum alcaguete, nas salas de 
aula. Afinal, a própria ex-diretora e fundadora da Faculdade, Irmã Sania Cosmelli, havia sido intimada a depor, na década de 1960, no Sanatório Naval da cidade, para explicar por que a Instituição tentara promover a palestra do "subversivo" jornalista Zuenir Ventura, filho dileto de Nova Friburgo. (SANTOS e CHALOUB, 2008, p. 126)

Apesar de todos os desafios impostos pelas leis 5.540/68 e 5.692/71, a Santa Dorotéia permaneceu durante todo o período da ditadura militar no Brasil ofertando diversificados cursos de licenciatura que contribuíram para a formação docente em Nova Friburgo e região e atuando como um polo de atividades de cunho educacional e cultural para toda a comunidade friburguense.

Com o fim da ditadura militar, os anos 1980 trouxeram um novo cenário para a educação em nível nacional. As críticas à formação de curta duração aumentaram muito. Por conta disso, ocorreram mudanças na legislação educacional da época para que houvesse uma retomada da ênfase na formação geral. Os debates no meio educacional tornaram-se mais intensos tanto acerca do ensino superior quanto em relação à educação básica.

A redemocratização do país veio acompanhada da necessidade de novas leis em todos os âmbitos, inclusive o educacional. Aprovou-se a nova Constituição Federal, em 1988 e passou-se a discutir uma nova lei de Diretrizes e Bases da Educação Nacional que só foi promulgada em 1996: a Lei 9.394/96.

Para além das questões legais, os anos 1990 já apresentavam uma nova realidade em relação à formação em nível superior na cidade de Nova Friburgo. Novas instituições educacionais deste nível se instalaram na cidade desde os anos 1970, com a chegada da Faculdade Cândido Mendes, e nos anos 1990 com as chegadas da Universidade do Estado do Rio de Janeiro (UERJ) com seu Instituto Politécnico, e da Universidade Estácio de Sá, dentre outras.

A chegada de novas instituições educacionais de nível superior na cidade de Friburgo, a vigência de nova legislação educacional, o encerramento das licenciaturas de curta duração, dentre outros fatos relevantes, acompanhou a necessidade de mudanças/alterações na organização burocrática, administrativa, legal, pedagógica, curricular, entre outras da FFSD.

Estas mudanças de cenário passaram a ser cada vez mais constantes, a partir dos anos 1990, e a necessidade de readaptação/modificação de questões variadas, desde o espaço físico, perpassando as avaliações externas, qualificação docente, adequações legais, administrativas, pedagógicas, curriculares, dentre outras vieram acompanhadas de dificuldades de adaptação da FFSD a tantas novas exigências. Ademais, a oferta de cursos de licenciatura, deixou de ser uma exclusividade da Faculdade de Filosofia Santa Dorotéia, em Nova Friburgo, o que significou concorrência num nicho que antes era somente de sua competência.

Em relação à cidade de Nova Friburgo, podemos dizer que os anos 1980/90 e a chegada do novo século vieram acompanhados de grandes dificuldades em função do declínio e fechamento de várias indústrias, o que gerou alto índice de desemprego e o empobrecimento da população friburguense. Para tentar superar a crise, a cidade teve que redirecionar suas prioridades econômico-produtivas para as confecções de moda íntima e para as diversificadas empresas do ramo metal-mecânico, de modo a poder oferecer oportunidades de trabalho e renda para a população local, além do incremento do comércio, uma atividade muito forte na cidade.

Novos cenários que foram se delineando trouxeram diversas dificuldades para a Santa Dorotéia, tais como: ampliação da inadimplência, necessidade constante de adaptações às exigências do Ministério da Educação (MEC) e da legislação educacional brasileira, dentre outras que se tornaram desafios difíceis de serem superados e acabaram contribuindo para o fechamento da FFSD no ano de 2014.

Para além dos fatos, parece-me necessário dizer que a escolha da Faculdade de Filosofia Santa Dorotéia como foco da pesquisa em andamento não está relacionada só a fatos ou a um simples interesse num objeto de pesquisa. Dialogamos com Alves $(2008$, p.18) para fundamentar a apresentação do espaço/tempo da FFSD para além dos fatos:

Assim, ao contrário da formação aprendida e desenvolvida na maioria das pesquisas do campo educacional, inclusive em muitas sobre o cotidiano escolar, que, de maneira 
muito frequente, têm assumido uma forma de pensar que vem negando o cotidiano como espaço/tempo de saber e criação, vou reafirmá-lo como sendo de prazer, inteligência, imaginação, memória e solidariedade, precisando ser entendido, também e sobretudo, como espaço/tempo de grande diversidade.[...] Buscar entender, de maneira diferente do aprendido, as atividades do cotidiano escolar ou do cotidiano comum, exige que esteja disposta a ver além daquilo que outros já viram e muito mais: que seja capaz de mergulhar inteiramente em uma determinada realidade buscando referências de sons, sendo capaz de engolir sentindo a variedade de gostos, caminhar tocando coisas e pessoas e me deixando tocar por elas, cheirando os odores que a realidade coloca a cada ponto do caminho diário.

Tudo que foi narrado até aqui evidencia a relação entre a trajetória da cidade de Nova Friburgo e a da FFSD, demonstrando como a Faculdade de Filosofia Santa Dorotéia esteve presente no cotidiano da cidade, exerceu papel importante e permanece presente na memória de muitas pessoas. Além de ter contribuído durante toda a sua existência para formar em diversificadas licenciaturas parte expressiva dos quadros docentes de Friburgo e dos municípios em seu entorno.

\section{O CAMPO DO CURRÍCULO E AS POLÍTICASPRÁTICAS COTIDIANAS.}

O termo currículo tem uma gama de possíveis definições conceituais que tentam dar conta de seus muitos significados possíveis. Vale ressaltar que não há um único conceito de currículo e sim variadas formas de concebê-lo e, com isso, defini-lo. Cabe a cada pesquisador operar com a definição mais adequada às suas próprias compreensões e ao desenvolvimento de sua pesquisa, apresentando os motivos que o levaram a esta escolha. De acordo com Domingues (1988, p.23), a palavra currículo:

só vai aparecer nos dicionários em 1856, com conteúdo muito especiais: "uma pista de corrida, um lugar para corrida, uma carreta de corrida; o termo é usado especialmente para referir-se a estudos universitários". Na edição de 1939, são omitidas as acepções 'corrida' e 'carreta' e acrescentada a expressão "um curso específico e fixo numa universidade". A edição de 1955 já adiciona "um curso, uma sequência de cursos numa escola ou universidade, com finalidade de graduação; conjunto total de cursos ensinados numa instituição educacional, ou departamento.

Claramente, as múltiplas possibilidades de compreender o termo dificultam a aceitação de uma única definição, porém, podemos afirmar que o termo faz parte do vocabulário obrigatório de todos os níveis e modalidades de ensino, incluindo os cursos de formação de professores, tanto de nível médio quanto de nível superior, na formação de mestres e doutores na área de Educação e também em documentos como: diretrizes, parâmetros, instrumentos legais diversos formulados em nosso país com o objetivo de direcionar as discussões acerca das bases curriculares de diversas áreas do conhecimento.

Portanto, refletir sobre currículo é pensar, por um lado, naquilo que se vai ensinar, conforme o afirmado pelas perspectivas mais tradicionais de currículo (SILVA, 1999), mas precisamos considerar que esta escolha se vincula a questões maiores como: o projeto de nação que se abraça, a importância da formação humana, na concepção de homem e de sociedade que se assume, envolve diversidade, pluralidade social e linguística, preparação para o mundo do trabalho e para a inserção crítico-cidadã no mundo em que vivemos, dentre outras temáticas que se constituem embates, tensões e dilemas presentes na área ou campo do conhecimento. Por outro lado, é pensar no dia a dia do trabalho das escolas e dos professores, e isso exige compreender o quanto os currículos reais são importantes de serem compreendidos como elemento basilar do processo ensino-aprendizagem, e são expressos por meio de conteúdos, conhecimentos, habilidades, atitudes, valores e experiências diversas, decorrente da reflexão-ação teórico-prática e didático-pedagógica dos professores com seus alunos. (REIS \& OLIVEIRA, 2018)

Isso demonstra a relevância dos estudos relacionados ao currículo e a multiplicidade de focos, embates, perspectivas, objetivos, dentre outros que podem ser desenvolvidos nas pesquisas e discussões sobre esse tema.

Neste estudo, nosso foco é apresentar a relevância de se trabalhar o termo currículo na perspectiva 
teórica nos/dos/com os cotidianos, além de demonstrar a relação existente entre currículo, formação docente, com foco na licenciatura em História e políticas públicas educacionais, a partir desta concepção teórica.

De acordo com o referencial dos estudos nos/dos/com os cotidianos, o currículo não pode ser pensado e nem separado das práticas cotidianas e relaciona-se diretamente com as políticas educacionais, ou seja, há sempre uma relação dialógica entre eles. Isso fica explícito nas palavras de Oliveira (2013, p. 379):

Nesse diálogo, posições e concepções diferenciadas a respeito do que é e deve ser a educação, o currículo, a sociedade e a prática educativa se expressam mais ou menos intensamente, em virtude do seu poder de intervenção sobre a produção das políticaspráticas curriculares, tanto em sua oficialidade textual quanto em sua realidade oficiosa. Ou seja, as políticas educacionais e as práticas cotidianas são produtos e produtoras de diálogos que as constituem e por elas são constituídos.

A concepção de currículo baseada nos estudos nos/dos/com os cotidianos está relacionada a movimento, a criação, a teoriaspráticascotidianas, a sujeitos praticantespensantes (OLIVEIRA, 2012). Embora se relacione, necessariamente, com os conteúdos de ensino, nada tem a ver com repetição ou aplicação de conteúdos, reproduções teóricas, imobilismo ou inércia.

Assim, falar em currículo como criação cotidiana pressupõe, entre outras coisas, que as diferentes formas de tecer conhecimentos - que estão na base de diferentes modos de agir, mesmo que jamais de modo linear - dialogam permanentemente umas com as outras, dando origem a resultados tão diversos quanto provisórios. Assim, nos diferentes e múltiplos momentos de suas vidas pessoais e profissionais, em virtude do acionamento de umas ou outras de suas subjetividades, em relação com outras diferentes e plurais redes de conhecimentos e sujeitos que habitam, fisicamente ou não, os cotidianos das escolas, os praticantespensantesdas escolas criam currículos únicos, inéditos, "irrepetíveis", alternativas aos problemas e dificuldades que enfrentam ao que não lhes agrada ou contempla, ao já existente e ao já sabido, contrariamente ao que supõem as perspectivas hegemônicas de compreensão dos currículos escolares, que os compreendem como um eterno reproduzir daquilo que foi previsto e prescrito. (OLIVEIRA, 2012).

Isso significa dizer que, nesta perspectiva, mesmo que as propostas privilegiem um ou outro aspecto dos conhecimentos de um campo e que as políticas oficiais definam metas específicas para o ensino, as práticas cotidianas jamais serão apenas obediência ou aplicação destas, elas conterão sempre mudanças, invenções e possibilidades nos usos que docentes e estudantes farão dessas normas e propostas.

\section{A FORMAÇÃO DOCENTE EM HISTÓRIA}

Entendendo que, o que efetivamente acontece nas salas de aula deve ser compreendido na perspectiva da criação cotidiana, para falarmos sobre a formação docente no campo da disciplina História, é importante apresentarmos uma contextualização da trajetória desta disciplina no nosso país em diálogo tanto com a formação docente em licenciatura na área quanto com as principais políticas educacionais brasileiras que a influenciaram.

Para iniciar esta discussão, não podemos deixar de mencionar os anos 1930 quando foi criado no nosso país o curso superior de História e Geografia, era um curso único destas duas disciplinas compiladas na maior parte das Universidades Brasileiras da época, com o objetivo de ofertar formação profissional para docentes da educação básica. É importante destacar que também nos anos 1930, foram criadas as primeiras Faculdades e Universidades que proporcionariam a formação de professores em nível de licenciatura no Brasil.

Já a década de 1950 deve ser citada como o período de criação da CAPES (Coordenação de Aperfeiçoamento de Pessoal de Nível Superior) e do CNPq (Conselho Nacional de Pesquisa, hoje Conselho Nacional de Desenvolvimento Científico e Tecnológico) abrindo caminho para a incipiente oferta de cursos de pós-graduação na área educacional em âmbito nacional. Além disso, foi no ano de 1955 que os 
cursos de História e Geografia foram desmembrados e tornaram-se cursos independentes, um marco importante para estas duas áreas do saber formal.

O ano de 1961 foi marcado pela promulgação da primeira Lei de Diretrizes e Bases da Educação Nacional, a lei 4.024/61, que alterou algumas relevantes questões referentes ao ensino superior. As palavras de Ferreira (2016, p. 24) ilustram bem esta questão: “A despeito das disputas, a LDB representou um passo importante para a reformulação do ensino superior, visando à expansão da pesquisa científica e estimulando a criação de cursos de mestrado e doutorado em diferentes universidades."

No ano de 1964, a instauração do golpe civil-militar marcou a história do nosso país e afetou diretamente os rumos educacionais brasileiros. Duas leis estabelecidas pelos militares alteraram os rumos do ensino superior e da educação primária e secundária no Brasil, a lei 5.540/68 e a lei 5.692/71, respectivamente. Estes dois documentos legais interferiram tanto na formação profissional docente no nível de licenciaturas quanto na estrutura e organização das instituições de ensino superior e, ainda, na estruturação da educação nacional. O estabelecimento das licenciaturas curtas com o propalado objetivo de profissionalização docente em menor tempo foi uma das principais marcas desse período.

No caso específico do ensino da História, a mudança mais significativa foi a criação de uma nova licenciatura, denominada Estudos Sociais, que reunia os conteúdos de História, Geografia e Organização Social e Política do Brasil. Os resultados dessas iniciativas não poderiam ser mais danosos tanto para os cursos de licenciatura, como para os alunos do ensino básico que se deparavam com currículos inadequados e docentes mal preparados. (FERREIRA, 2016, p. 33)

A nova licenciatura denominada Estudos Sociais foi criada para dar conta dos estudos das ciências sociais no $1^{\circ}$ grau, que reunia na nova Lei os conteúdos de História, Geografia e, um terceiro componente, com nomes distintos em diferentes níveis de escolarização: Educação Moral e Cívica no Ensino Fundamental, Organização Social e Política do Brasil no nível médio e, Estudo de Problemas Brasileiros, no ensino superior.

É importante ressaltar que o autoritarismo e o controle político-ideológico foram uma marca dos anos 1964-1985, ao longo da ditadura militar no nosso país, que interferiu muito na educação em geral e na formação de professores em particular, em todos seus níveis.

Os anos 1980 foram marcados pela abertura política e pelo fim da ditadura militar no Brasil, abrindo caminho para um novo momento na história e trajetória política do país, deixando também sua marca na formação docente e nas políticas públicas educacionais no nosso país.

As discussões que se estenderam pela década de 1980 apontavam para a superação das concepções presentes na legislação do regime militar. Nesse sentido, crescia a demanda por uma educação voltada para a formação de cidadãos, o que deveria ser refletido em todos os níveis de ensino e, especialmente, na formação de professores e, após a promulgação da Constituição Cidadã em 1988, se iniciaram os debates para a formulação de uma nova LDB. Debates intensos foram realizados e um projeto efetivamente democrático de LDB surgiu, mas a vitória de Fernando Henrique Cardoso nas eleições de 1994 fez com que o projeto sofresse inúmeras mudanças, que adulteraram muito do seu ideário democrático. A proposta modificada a partir do projeto apresentado ao Senado por Darcy Ribeiro foi aprovada em dezembro de 1996, se tornando a nova Lei de Diretrizes e Bases da Educação Nacional, Lei $9.394 / 96$.

Retomando a questão da formação docente em História e do currículo das licenciaturas desta disciplina, a partir dos anos 1990, as palavras de Ferreira (2016, p.35) são relevantes,

No caso dos cursos de História, o que se verifica é uma constante preocupação com a integração entre as duas formações: a do pesquisador e a do professor. Essa preocupação, contudo, nem sempre se reflete na organização curricular dos diferentes cursos em que, frequentemente, as disciplinas de bacharelado são somadas às disciplinas pedagógicas, oferecidas e geridas pelas faculdades de Educação para compor o currículo da licenciatura. 
A partir do que foi exposto na citação acima fica evidente que há na formação dos licenciados em História, a partir dos anos 1990, um embate na composição curricular deste curso de graduação acerca do peso e do papel formativo das disciplinas pedagógicas voltadas para o campo da formação do professor e das disciplinas específicas de História voltadas para a formação do historiador e do pesquisador nesta área, além dos problemas inerentes às impossibilidades de incorporação pelos docentes em seus cotidianos de determinadas propostas e exigências.

Em torno deste embate podemos levantar algumas questões que permeiam a formação do licenciando em História até os dias atuais: Quais as disciplinas/práticas necessárias para formar um bom professor de História? O número maior de disciplinas específicas do campo da História no currículo da licenciatura contribuirá para se formar um professor de História mais preparado para dar aulas desta disciplina na Educação Básica? Por que precisamos de tantas disciplinas pedagógicas na formação? Estas e outras perguntas perpassaram a formação da pesquisadora e a dos seus colegas durante toda a licenciatura.

É evidente que há uma diferença expressiva entre a formação de pesquisadores e a formação docente, na área de História e em outras. Assim como fica claro que há nas licenciaturas em História um embate sobre o equilíbrio possível e necessário entre conhecimentos pedagógicos e conhecimentos específicos da disciplina de História na composição curricular da graduação nesta área.

Após a recuperação de alguns dos principais elementos que envolveram historicamente as propostas de formação docente em nível de licenciatura, presentes nas diferentes políticas educacionais oficiais, daremos foco a seguir na composição/alterações curriculares da licenciatura em História da Faculdade de Filosofia Santa Dorotéia no século XXI, entre os anos de 2001-2009, e a sua relação com as políticas educacionais brasileiras em vigor neste período.

Além de buscarmos compreender a relação estabelecida na licenciatura em História da FFSD acerca da tensão entre conhecimentos/disciplinas do campo pedagógico e do campo disciplinar da História.

\section{AS ALTERAÇÕES CURRICULARES NA LICENCIATURA EM HISTÓRIA DA FFSD NO SÉCULO XXI}

As reflexões apresentadas acima acerca dos estudos sobre currículo e sobre a formação de professores no nível da licenciatura em História, seguimos dando ênfase às relações entre o que mencionamos até aqui acerca das políticas educacionais brasileiras, da formação de professores em nível superior e das tensões na composição curricular das licenciaturas em História, focando nossa atenção na trajetória do curso de licenciatura em História da Faculdade de Filosofia Santa Dorotéia, ao longo do século XXI.

Para tal, analisaremos as alterações curriculares da licenciatura em História da FFSD ocorridas nos anos de 2001 e 2006 relacionando-as aos documentos legais da área de Educação vigentes no nosso país, além das relações com as questões curriculares referentes à formação de professores em geral e no campo da História em particular.

A primeira alteração curricular da licenciatura em História, no ano de 2001, teve como principal mudança a inclusão da disciplina de Prática/Estágio Supervisionado, desde o primeiro até o último (oitavo) período da licenciatura em História.

Sobre esta alteração, podemos incluir um relato pessoal, de quem ingressou na FFSD no ano de 2002, numa turma que esteve sob a égide deste novo currículo da licenciatura em História, iniciado em 2001. Para dar conta da oferta da disciplina de Prática/Estágio Supervisionado desde $01^{\circ}$ período do curso, a FFSD passou a oferecê-la aos sábados pela manhã, o que era extremamente cansativo, pois vínhamos de uma rotina de aulas noturnas ao longo de toda a semana. Além disso, era também um complicador para os colegas que trabalhavam no comércio e em outras atividades laborais que incluem o sábado como dia de trabalho semanal. Outro complicador incluía a pesquisadora e alguns outros colegas que não moravam em Nova Friburgo, pois o transporte escolar ofertado pelos municípios de entorno, para levar estudantes universitários para suas aulas em Nova Friburgo, não funcionava aos sábados, o que gerava transtornos de deslocamento, além de despesas extras com passagem e alimentação.

Para dar conta das Práticas ao longo de todo o curso, uma das alternativas encontradas pelo 
coordenador do curso de História, junto com os demais docentes do curso da Santa Dorotéia foi integrar essa disciplina às pesquisas na área de história regional, sempre muito incentivadas na FFSD. Passamos dois períodos frequentando o arquivo municipal Pró-Memória, responsável por arquivar documentos diversos: livros, fotos, jornais, etc. sobre a história de Nova Friburgo e região, para termos contato com a pesquisa e sermos incentivados a pesquisar.

Outra medida importante foi a de firmar um acordo com o Instituto de Educação de Nova Friburgo (IENF), tradicional escola da rede estadual de ensino voltada para o curso normal, para que ministrássemos aulas coletivas sobre nossas pesquisas referentes à história de Nova Friburgo para as normalistas, cumprindo assim uma das prerrogativas da disciplina de Prática/Estágio supervisionado.

A experiência citada nos parágrafos anteriores demonstra como as reinvenções curriculares cotidianas estavam presentes nas teoriaspráticas desenvolvidas pelos docentes da FFSD. Este repensar do currículo, para além da formalidade curricular, levando em conta os desafios das alterações do novo currículo (2001), o desejo de incluir a pesquisa na formação discente, de transformar o estágio num momento de compartilhar ensinosaprendizagens, dentre outras questões é que faz com que o currículo vivenciado na prática docente vá além da proposta formal de conteúdos, diretrizes, parâmetros, etc.

Questões que consideramos relevantes acerca das alterações no currículo da licenciatura em História da FFSD precisam ser apresentadas aqui, e para abordá-las apresentamos a composição dos currículos de 2001 e 2006, além de tecer relações entre as mudanças/ alterações ocorridas em cada um deles.

Para facilitar o entendimento das permanências e ausências na composição dos currículos em estudo, fizemos uma separação das disciplinas em três núcleos: núcleo básico, núcleo pedagógico e núcleo específico, criando assim categorias de análise. Esta separação não é simples, pois algumas disciplinas poderiam estar presentes em mais de um núcleo, mas utilizamos este mecanismo para tentar dar mais clareza ao artigo, facilitando a compreensão pelos leitores.

O currículo da licenciatura em História vigente na FFSD a partir do ano de 2001 apresentava um total de 3.210 horas. O núcleo básico era composto por disciplinas como: Informática, Leitura e Produção de Texto I, II e III, Filosofia I, II, III e IV, Metodologia do Trabalho Acadêmico, Metodologias e Técnicas de Pesquisa I e II, Cultura Religiosa I, II e III, Sociologia I e II e Antropologia I, II, III, IV e V com um total de 645 horas.

Vale ressaltar que as disciplinas de Sociologia e Antropologia foram incluídas no núcleo básico ou de formação geral por serem disciplinas do campo das ciências sociais e terem um relevante papel formativo para os profissionais das chamadas ciências humanas e sociais. Porém, a presença destas disciplinas no currículo da licenciatura em História da FFSD perdeu bastante força nas mudanças/ajustes curriculares seguintes.

O outro núcleo, que chamaremos de pedagógico, apresentava as seguintes disciplinas: Filosofia da Educação I e II, Didática I, II e III, Metodologia do Ensino de História I, II e III, Estrutura e Funcionamento do Ensino, Psicologia da Educação I e II e Prática/ Estágio Supervisionado I, II, III, IV, V, VI, VII, VIII e IX. Perfazendo um total de 1.140 horas distribuídas da seguinte maneira: 330 horas (disciplinas citadas) + 810 horas (Prática/Estágio Supervisionado).

Já o que denominamos núcleo específico tinha 1.425 horas. As disciplinas que compunham este núcleo: Teoria da História I e II, História Antiga e Medieval I, II e III, História da Arte I e II, História Moderna e Contemporânea I, II, III e IV, História do Brasil I, II, III e IV, História da América I, II, III e IV, Historiografia, História Regional I e II, Geohistória, Historiografia, História Econômica, Política e Social (Geral e do Brasil), I, II, III e IV.

No currículo da licenciatura em História vigente na FFSD a partir do ano de 2006, as mudanças em relação ao currículo anterior, de 2001, foram muitas. A inclusão de algumas disciplinas se deu em função da promulgação de documentos legais que entraram em vigor no nosso país como, a Resolução CNE/CP 
$n^{\circ} 2 / 2002$ e a lei $n^{0} 10.639 / 2003^{3}$, que interferiram diretamente na composição curricular da formação docente em geral e das licenciaturas em História em particular. Sobre esta questão da interferência legal na composição do currículo das licenciaturas, as palavras de Caimi (2013, p. 203) são bastante relevantes:

Um dos aspectos mais polêmicos presentes nas novas diretrizes para a formação de professores refere-se à exigência de elevar a carga horária das disciplinas/atividades de prática pedagógica e de estágios para 800 horas. A Resolução CNE/CP n 2/2002 estabelece, no Artigo $1^{\circ}$, que a carga horária dos cursos de Formação de professores da Educação Básica, em nível superior, em curso de

licenciatura, de graduação plena, será efetivada mediante a integralização de, no mínimo, 2.800 (duas mil e oitocentas) horas, assim distribuídas: 400 (quatrocentas) horas de prática como componente curricular, vivenciadas ao longo do curso; 400 (quatrocentas) horas de estágio curricular supervisionado a partir do início da segunda metade do curso; 1.800 (mil e oitocentas) horas de aulas para os conteúdos curriculares de natureza científico-cultural; 200 (duzentas) horas para outras formas de atividades acadêmico-científico-culturais.

A primeira década do ano 2000 foi permeada por diversas discussões acerca da Educação nacional, da formação docente e de questões sociais relacionadas à inclusão de diversos grupos considerados excluídos da sociedade brasileira seja por questões raciais, econômicas, de gênero, de sexualidade, de deficiências, dentre outras, o que gerou uma série de dispositivos legais e de políticas públicas visando a garantir os direitos destes grupos na sociedade e, especificamente, no campo educacional.

As palavras de Caimi (2013, p. 194) acerca destas políticas e documentos legais instituídos na área educacional, especialmente na formação de professores de forma ampla e no campo específico da História, a partir das demandas sociais apresentadas acima, nos ajudam na compreensão dos debates do período. Diz a autora,

[...] estendeu-se o olhar para algumas das políticas relativas às Licenciaturas em História, focalizando especialmente o Parecer CNE/CP 09/2001 que estabelece as Diretrizes Curriculares Nacionais para a Formação de Professores da Educação Básica, em nível superior, curso de licenciatura, de graduação plena; o Parecer CNE/CES n $492 / 2001$, que estabelece as Diretrizes Curriculares Nacionais dos Cursos de História; a Lei $\mathrm{n}^{\circ}$ 10.639/2003, que torna obrigatória a inclusão de História e Cultura Afro-brasileira nos currículos escolares; a Lei $n^{\circ} 11.645 / 2008$, que torna obrigatório, nos estabelecimentos de ensino fundamental e de ensino médio, públicos e privados, o estudo da história e cultura afro-brasileira e indígena; e o Decreto $\mathrm{n}^{\circ} 5.626 / 2005$, que estabelece a inserção de Língua Brasileira de Sinais (Libras) como disciplina curricular obrigatória nos cursos de formação de professores para o exercício do magistério, em nível médio e superior.

Para adequar-se às diversificadas normas legais que passaram a vigorar no Brasil, referentes a variados campos da Educação e da História foi necessária a alteração/ readequação do currículo da licenciatura em História da FFSD no ano de 2006.

Para falar das alterações feitas no currículo de 2006, iniciaremos pela disciplina de Prática/Estágio Supervisionado que foi desmembrada em Prática de I ao VIII, uma disciplina com conteúdos especificados no currículo, e Estágio Supervisionado.

A especificação dos conteúdos na disciplina de Prática foi uma importante mudança, pois incluiu, mesmo que indiretamente, no currículo questões contemporâneas que permeiam o ensino de História e especificou os conteúdos a serem trabalhados em cada período de Prática, perfazendo uma carga horária de 408 horas-aula. Já o Estágio Supervisionado passou a ter uma carga horária específica de 400h.

Além disso, neste currículo foi incluída a obrigatoriedade de atividades acadêmico-científicoculturais que passaram a compor a carga horária do curso, num total de $200 \mathrm{~h}$ para que os licenciandos comprovassem a participação em atividades diversas como: palestras, debates, idas a eventos culturais

\footnotetext{
${ }^{3}$ A lei $n^{\circ}$ 10.639/2003 foi alterada pela lei 11.645/2008 e passou a incluir no currículo oficial da rede de ensino a obrigatoriedade da temática "História e Cultura Afro-Brasileira e Indígena".
}

Rev. Espaço do Currículo (online), João Pessoa, v.13, n.3, p. 487-501, set/dez. 2020. 
ISSN $1983-1579$

Doi: $10.22478 /$ ufpb.1983-1579.2020v13n3.54568

http://periodicos.ufpb.br/ojs2/index.php

como: cinema, teatro, dentre outros.

O currículo de 2006 ficou estruturado da seguinte maneira: 2.941 horas-aula distribuídas entre as disciplinas que compunham o currículo somadas a 600 horas que estavam divididas da seguinte forma: Estágio Supervisionado (400 h) e Atividades Acadêmico-Científico-Culturais (200h) perfazendo um total geral de 3.541 horas.

Em 2006, o núcleo básico perdeu a disciplina de Metodologia do Trabalho Acadêmico, Filosofia III e IV, Sociologia II e Antropologia IV e V e manteve as demais disciplinas já existentes no currículo de 2001, passando a ter uma carga horária de 557 horas-aula.

Já o chamado núcleo pedagógico perdeu as disciplinas de Filosofia da Educação II, Didática III, Psicologia da Educação II e Estrutura e Funcionamento do Ensino e ficou composto pelas seguintes disciplinas: Filosofia da Educação, Psicologia da Educação, Didática I e II, Metodologia do ensino de História, Políticas Públicas em Educação. Nota-se a inclusão de uma nova disciplina: Políticas Públicas em Educação, fundamental para discutir esta temática tão relevante para a docência e para a compreensão do sistema educacional. Perfazendo um total de 255 horas-aula.

A apresentação permite perceber a diminuição do número de disciplinas relacionadas às ciências sociais, à filosofia e ao campo pedagógico no currículo de 2006. As disciplinas de Metodologia do Ensino de História II e III não constam no currículo de 2006, mas pode-se afirmar que foram abarcadas por conteúdos incluídos nas disciplinas de Prática.

Em relação à carga horária, o núcleo pedagógico ficou com 255 horas-aula nas disciplinas +408 horas-aula de Práticas (I ao VIII) + 400 horas de Estágio Supervisionado, num total de 1.063 horas. Já o núcleo básico organizou-se da seguinte maneira: 557 horas-aula das disciplinas + 200 horas de Atividades Acadêmico-Científico-Culturais, chegando ao valor de 757 horas. E o núcleo específico, com um total de 1.721 horas-aula, teve adicionadas algumas novas disciplinas: Geohistória II, História da África I e II e outras disciplinas mudaram de nome, como Teoria da História I e Il que se transformou em Teoria e Metodologia da História I e II, disciplina esta que perpassa o núcleo específico e também o pedagógico, tecendo uma relevante ligação entre eles. Outras disciplinas se desmembraram para aprimorar a distribuição do conteúdo entre elas, caso de: História Antiga e Medieval I, II e III que se transformou em História Antiga I e II e História Medieval I e II.

No núcleo específico precisamos destacar a criação de História da África I e II, pois a inclusão desta disciplina se deu em função da Lei n ${ }^{\circ}$ 10.639/2003 que tornou obrigatória a inclusão de História e Cultura Afro-brasileira nos currículos escolares como já mencionamos, o que se refletiu na formação profissional docente da área de História, um claro exemplo da influência de documentos legais na composição curricular das graduações em História e na formação docente dessa área.

Já a inclusão de uma disciplina de Libras (Língua Brasileira de Sinais), de acordo com o Decreto $\mathrm{n}^{\circ}$ $5.626 / 2005$, só se deu na alteração curricular do ano de 2009, porém não trataremos deste que foi o último currículo em vigência na FFSD ao longo deste artigo.

Após esta análise comparativa dos currículos que compuseram o curso de licenciatura em História da FFSD, entre 2001-2009, ficou claro que a Faculdade sempre tentou manter o currículo do curso de licenciatura em História, adequado às políticas educacionais para a formação docente, expressas em uma série de documentos legais referentes tanto à formação docente no nível de licenciatura quanto às exigências relacionadas ao campo específico da História. Para tal, reformulou sempre que necessário o currículo da licenciatura em questão como vimos ao longo deste artigo.

Apesar disso, a tensão existente na maior parte dos cursos de licenciatura em História entre a composição curricular do núcleo específico e do núcleo pedagógico se mostrou presente também na licenciatura em História da FFSD. Nos dois currículos estudados (2001, 2006), mesmo com percentuais variáveis entre eles acerca do número de horas-aula destinadas ao núcleo específico, este sempre foi composto por um número bem maior de horas-aula em relação ao núcleo pedagógico, o que não está em conformidade com as orientações legais referentes à formação de professores em nível superior. 
Ademais, não parece haver uma interlocução, um entrelace entre estes dois núcleos, específico e pedagógico, tão importantes para a formação de professorxs de História.

Não apresentamos nenhuma experiência discente referente ao currículo de 2006 no artigo, pois ainda não tivemos contato com egressos do curso de licenciatura em História sob a vigência deste currículo, o que deverá ocorrer ao longo da pesquisa de Doutorado no qual este estudo se insere. Porém, sabemos que as teoriaspráticas desenvolvidas pelo corpo docente, ou por parte dele, permaneceram produzindo reinvenções curriculares cotidianas também ao longo da vigência deste currículo, o que imaginamos poder confirmar na sequência da pesquisa.

Consideramos que a análise das mudanças curriculares realizadas no curso de licenciatura em História da FFSD entre os anos de 2001-2009 foi desenvolvida de maneira satisfatória até aqui, abrindo caminho para o último passo a ser desenvolvido neste artigo que é parte de pesquisa maior sobre a instituição e suas licenciaturas.

\section{CONSIDERAÇÕES FINAIS}

Depois de fazermos um breve histórico do entrelaçamento das trajetórias da cidade de Nova Friburgo e da Faculdade de Filosofia Santa Dorotéia (FFSD), com o objetivo de apresentar para os leitores, características relevantes da instituição educacional a que demos foco neste estudo e da cidade que a abrigou, finalizamos este artigo nos debruçando sobre a discussão a respeito da composição curricular da licenciatura em História da FFSD nos anos iniciais do séc. XXI, entre 2001 e 2009.

Ao longo do século citado, ficou evidente que as políticas educacionais brasileiras impuseram variadas mudanças em relação à formação docente e à composição curricular dos cursos de licenciatura da área de História.

Depois de mergulharmos na composição dos currículos de História vigentes na Faculdade Santa Dorotéia entre os anos de 2001 a 2009 e demonstrarmos como se deram as permanências e as distinções presentes nestes currículos, pudemos verificar que estes seguiram as exigências da legislação educacional em vigor no nosso país no período estudado, fazendo sempre que necessário, ajustes nos currículos para adequá-los ao que a legislação exigia sem perder de vista o objetivo maior de ofertar uma formação ampla e diversa, contemplando demandas da área da Educação e da História contribuindo para que estes sujeitos praticantespensantes viessem a se tornar professorxs preparados para atuar na educação básica.

Em contrapartida, precisamos destacar a ênfase dada às disciplinas componentes do chamado núcleo específico-histórico nos dois currículos avaliados (2001 e 2006), o que demonstra que o curso de licenciatura em História da FFSD seguiu um modelo curricular comumente colocado em prática pela maior parte dos cursos de licenciatura nesta área do conhecimento, valorizando o núcleo de formação específica em detrimento do chamado núcleo pedagógico e da interface entre eles.

Porém, a experiência da pesquisadora quando foi discente na instituição, confirma que, nos cotidianos da formação, os docentes buscavam atuar de modo a favorecer a articulação entre as dimensões do currículo oficial, contribuindo com isso, para a superação de marcas legais presentes na própria cultura da formação que apartam as esferas da formação geral, específica e pedagógica, na tentativa de integrá-las e não de dissociá-las.

Com isso, podemos finalizar este artigo afirmando que a FFSD deixou um importante legado para seus egressos, além de possíveis marcas positivas na atuação docente da educação básica da cidade de Nova Friburgo e municípios ao seu entorno, onde muitos dos ex-alunos do curso de História da FFSD atuam como professores, seja na rede pública ou na rede privada, no ensino fundamental e/ou no ensino médio, tema este não aprofundado no presente artigo, mas também relevante na pesquisa em desenvolvimento. 


\section{REFERÊNCIAS}

ALVES, Nilda. Decifrando o pergaminho - os cotidianos das escolas nas lógicas das redes cotidianas. In: ALVES, Nilda; OLIVEIRA, Inês Barbosa de (orgs.). Pesquisa nos/dos/com os cotidianos das escolas sobre redes de saberes. $3^{\text {a }}$ ed. Petrópolis/RJ: DP et Alli, 2008.

CERTEAU, Michel de. A invenção do cotidiano: artes de fazer. Petrópolis: Vozes, 1994.

DOMINGUES. José Luiz. O cotidiano da escola de $1^{a}$ grau: sonho e a realidade. Goiânia, CEGRAF/UFG; São Paulo, EDUC- Ed. da PUCSP. 1988.

CAIMI, Flávia Eloisa. A licenciatura em História frente às atuais políticas públicas de formação de professores: um olhar sobre as definições curriculares. Porto Alegre, RS: Revista Latino-Americana de História, vol.2, n 6, p. 193-209, agosto de 2013.

FERREIRA, Marieta de Moraes. O ensino da História, a formação de professores e a pós-graduação. Porto Alegre, RS: Revista Anos 90, vol. 23, nº 44, p. 21-49, dez. 2016.

LIBANEO, José Carlos, OLIVEIRA, João Ferreira de, TOSCHI, Mirza Seabra. Educação Escolar: políticas, estrutura e organização. São Paulo: Cortez, 2003. (Coleção Docência em Formação).

SANTOS, Selma Ferro dos. CHALOUB, Vera Rezende. (org). Faculdade de Filosofia Santa Dorotéia: uma história. Nova Friburgo, RJ: Imagem Virtual, 2008.

OLIVEIRA, Inês B. O Currículo como criação cotidiana. Petrópolis, RJ: DP et Alli, 2012.

- Currículo e Processos de Aprendizagemensino: Políticaspráticas educacionais cotidianas. Currículo sem Fronteiras, v. 13, n. 3, p. 375-391, set./dez. 2013.

REIS, Geovana; OLIVEIRA, João Ferreira de. A Constituição do currículo escolar no Brasil: dilemas, impasses e perspectivas. Disponível em: http://sites.pucgoias.edu.br/pos-graduacao/mestrado-doutoradoeducacao/wp-content/uploads/sites/61/2018/05/Geovana-Reis_-Joao-Ferreira-de-Oliveira.pdf, 2018. Acesso em: 10 de jul de 2020.

Recebido em: 15/08/2020

Aceito em: 09/10/2020

Publicado em: 09/11/2020 